\title{
Association of Interferon-gamma Gene Polymorphism (+874 A/T) and Oral Lichen planus susceptibility: Systematic Review and Meta- Analysis
}

\author{
Paria Motahari $^{1 *}$, Fatemeh Pournaghi Azar ${ }^{2}$, Parisa Rasouly ${ }^{1}$
}

1. Department of Oral Medicine, Faculty of Dentistry, Tabriz University of Medical Sciences, Tabriz, Iran

2. Research center for evidence based medicine, Dental Faculty, Tabriz University of Medical Sciences, Tabriz, Iran

\section{Article Type:}

Systematic Review and Meta-Analysis

\section{Article History:}

Received: 15 Mar 2019

Revised: 30 Apr 2019

Accepted: 15 Aug 2019

\section{*Correspondence:}

Paria Motahari

Department of Oral Medicine, Faculty of Dentistry, Tabriz University of Medical Sciences, Tabriz, Iran

paria@motahari.com

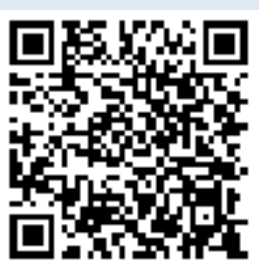

\begin{abstract}
Background and objectives: Most studies have identified interferon-gamma (IFN- $\gamma$ ) as a key role in the pathogenesis of oral lichen planus (OLP). Recent studies have also shown a link between IFN- $\gamma(+874 \mathrm{~A} / \mathrm{T})$ gene polymorphism and OLP. The purpose of the present meta-analysis is to investigate the relationship between IFN- $\gamma(+874 \mathrm{~A} / \mathrm{T})$ gene polymorphism and susceptibility to OLP.
\end{abstract}

Methods: A systematic search of resources to investigate the association between IFN- $\gamma$ and OLP from Google scholar, PubMed, Embase, Cochrane, Scopus, Proquest, Ovid and Web of science (from 2000 to April 2019) completed. Two individuals independently assessed the quality of the articles. Endnote X5 resource management software was used to organize, study titles and abstracts as well as identify duplicates. A random effect model was also used to perform the meta-analysis.

Results: Four IFN- $\gamma(+874$ A/T) polymorphism studies with 297 patients in the case group and 621 healthy controls in the 4 different countries were included. After metaanalysis, a significant association was found between IFN- $\gamma$ polymorphism $(+874 \mathrm{~A} / \mathrm{T})$ and OLP. ( $\mathrm{T}$ vs $\mathrm{A}$ : odds ratio $(\mathrm{OR})=1.62 ; 95 \% \mathrm{CI}=1.28-2.04$; $\mathrm{TT}$ vs $\mathrm{AA}$ : $\mathrm{OR}=2.67$; $95 \% \mathrm{CI}=1.6-4.45 ; \mathrm{AT}$ vs $\mathrm{AA}: \mathrm{OR}=1.56 ; 95 \% \mathrm{CI}=1.6-4.45 ; \mathrm{TT}$ vs $\mathrm{AT}+\mathrm{AA}: \mathrm{OR}=$ $1.73 ; 95 \% \mathrm{CI}=1.13-2.64 ; \mathrm{AT}+\mathrm{TT}$ vs $\mathrm{AA}: \mathrm{OR}=1.75 ; 95 \% \mathrm{CI}=1.28-2.43$ )

Conclusion: Based on this meta-analysis, there was a positive relationship between IFN$\gamma(+874 \mathrm{~A} / \mathrm{T})$ gene polymorphism and the risk of OLP. The findings showed that increasing TT genotypes significantly increased susceptibility to OLP in comparison with other genotypes.

Keywords: oral lichen planus, gene polymorphism, IFN- $\gamma$

Copyright $@$ 2018, Jorjani Biomedicine Journal has published this work as an open access article under the terms of the Creative Commons Attribution License (http://creativecommons.org/licenses/by-nc/4.0/) which permits noncommercial uses of the work while it is properly cited. 


\section{Introduction}

Oral lichen planus (OLP) is a chronic inflammatory disease that affects $1-2 \%$ of adults (1). The results show OLP is reticular white lesions that are usually bilateral, seen in the oral mucosa and sometimes in the tongue. In some cases, these lesions are associated with mucosal ulcers (2-4). Although the mechanism of lichen planus pathogenesis is not completely clear, it is commonly known as an immunological disease. Microscopically, it is similar to T-cell hypersensitivity reaction (3). The role of cytokines associated with $\mathrm{T}$ cells has been studied in recent decades. Among these cytokines, interferon-gamma and interleukine-4 (IL-4) have been further investigated, because IFN- $\gamma$ and IL-4 are specific cytokines for $\mathrm{T}$ helper (TH) 1 and $\mathrm{T}$ helper 2 cells, respectively $(3,5)$. IFN- $\gamma$ is a soluble cytokine, also known as a macrophage activating factor(6). This cytokine plays an important role in the immune process, especially against viral infection, intracellular bacteria and tumor control (7). Research has shown that Th1/Th2 imbalance is involved in the pathogenesis and development of many types of autoimmune diseases (8). Since OLP has an immunologic basis, it appears that cytokine proteins frequently change during this disorder (9). Therefore, achieving a coherent result helps us to understand the pathogenesis of this disease. Many studies have been done to evaluate the cytokines in Lichen planus. Among the masses of cytokines studied, IFN- $\gamma$ was the target of our systematic study.

The IFN- $\gamma$ coding gene is located on chromosome 24q12 and contains four exons and three introns. Polymorphisms at the site of the first intron in the +874 region (rs2430561) increase IFN- $\gamma$ production (10, 11). Studies in China, Thailand, and Italy have shown a link between IFN- $\gamma$ gene polymorphism and OLP (12-14). In some of these studies, no association was found between $(+874 \mathrm{~A} / \mathrm{T})$ gene polymorphisms and autoimmune diseases $(15,16)$.

Due to the small volume of individual studies and other limitations, these studies have low statistical power and are poor in estimating disease risk, Also, due to inconsistent conclusions in this field, the aim of the present study was to identify and comprehensively analyze all relevant clinical studies to investigate the association of the IFN- $\gamma$ gene polymorphism $(+874 \mathrm{~A} / \mathrm{T})$ and susceptibility to oral lichen planus. These results may provide further evidence for understanding the pathogenesis and progression of OLP, as well as a pathological basis for physicians, for better treatment and for prognosis.

\section{Materials and Methods}

\section{Identify eligible studies}

A systematic search of resources was conducted to investigate the association between IFN- $\gamma$ gene polymorphism and susceptibility to OLP in accordance to Preferred Reporting Items for Systematic Reviews and Meta-Analysis (PRISMA) guidelines (17). The Google scholar, PubMed, Embase, Cochrane, Scopus, Proquest, Ovid and Web of science databases from January 2000 to April 2019 were used to search articles. From the combination of keywords; selected based on MESH and Embase (" Oral precancerous lesion (s) " OR " oral lichen planus" OR " oral premalignant lesion (s) " OR "OLP") AND (" Interferon gamma " OR " IFN " OR " IFN- $\gamma$ " OR "Interferon $\gamma$ ") AND 
(" polymorphism " OR " allele " OR " variant " OR " single nucleotide polymorphism " OR " SNP " were used. In addition, the reference lists in related articles and reviews are also considered eligible studies. Data were extracted by two reviewers using data extraction form and according to the inclusion and exclusion criteria. In times of disagreement, a third reviewer was used.

Ethical approval and informed consent were not required for this study, as these studies were based on previously published articles.

\section{Inclusion and exclusion criteria}

Inclusion criteria included: English language case-control study, cohort, and crosssectional. Clinical studies focusing on the relationship between the IFN- $\gamma$ gene and the risk of OLP, published between 2000 and April 2019. Also, patients in the patient group should have no other disease than lichen planus.

The number of studies for a single gene locus (SNP) should not be less than 3 studies. Exclusion criteria were as follows: animal studies, laboratory studies, systematic reviews, case reports, invalid theories, or studies without accurate genotype data to calculate odds ratios (ORs) and 95\% confidence intervals (CIs) needed.

\section{Data mining and quality assessment}

The articles were extracted from the databases using the mentioned keywords and were selected by the subject expert in three stages. First, the titles of all articles were reviewed, and articles that were incompatible with the study objectives were excluded. Abstracts and full texts of the articles were studied and studies with exclusion criteria with poor correlation with study objectives were identified and excluded. The studies selected by the two reviewers were evaluated for risk of bias and in times of disagreement were referred to a third reviewer.

Required information extracted from the articles was summarized in Extraction form. Information extracted included: author's name, year of publication, individual characteristics (including number of patients in groups, age, and sex), country and genotyping method. Endnote X5 resource management software was used to organize, study titles and abstracts as well as identify duplicates. Quality assessment of obtained articles was performed according to the checklist which was provided by the Joanna Briggs Institute (18).

\section{Statistical analysis}

The probability of each allele and genotype in the patient group was compared to the control group in the meta-analysis. Pooled ORs were calculated for allelic model ( $\mathrm{T}$ vs A), homozygote model (AA vs TT), heterozygote model (AT vs AA), dominant model (TT+AT vs AA), and recessive model (TT vs AA+AT). Heterogeneity between studies was assessed by Cochran's statistics (Q) and I2, which expressed the percentage of variation between studies. I2 values $25 \%$, $50 \%$ and $75 \%$ were considered to present low, moderate and high levels of heterogeneity, respectively. Statistical analysis was performed using CMA v.3.0 software and pvalue less than 0.05 was considered as significant level.

\section{Results}

\section{Characteristics of included studies}

A systematic search of sources identified 1022 articles. 484 articles were excluded due 
to duplication and 530 articles after reviewing the title and review of the abstracts were excluded. After reviewing the full text articles, 4 articles were excluded from the study. Finally, 4 articles were included in this meta-analysis study. The flow chart for the identified and imported articles is shown in Figure 1. The characteristics of the included studies and patients are shown in Table 1.

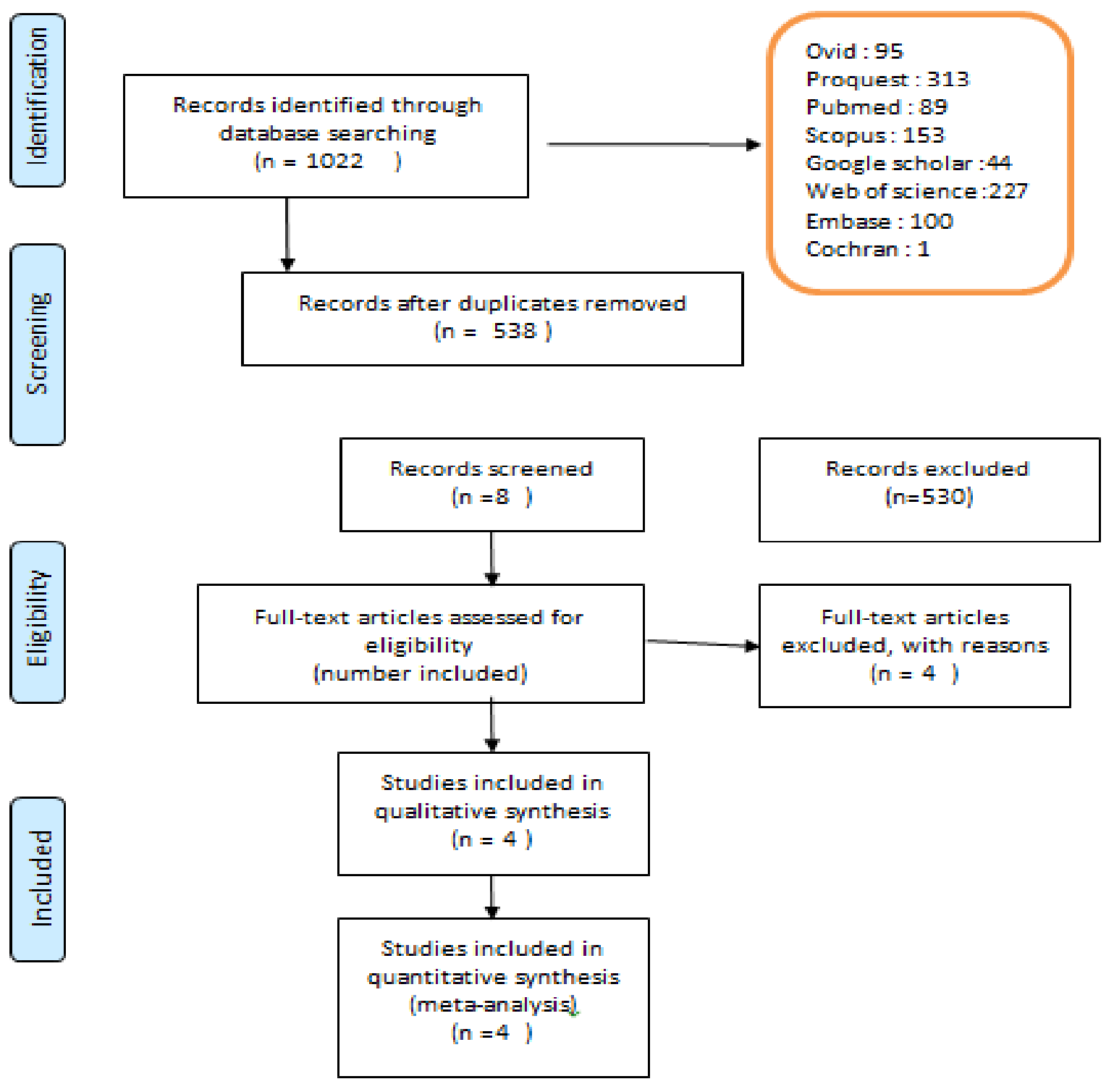

Fig. 1: The flowchart of searching strategy based on PRISMA guidelines. 
Table 1: Characteristics of studies included in the meta-analysis.

\begin{tabular}{|c|c|c|c|c|c|c|c|c|}
\hline \multirow{2}{*}{$\begin{array}{l}\text { Firs } \\
\text { author }\end{array}$} & \multirow[b]{2}{*}{ Year } & \multirow{2}{*}{$\begin{array}{l}\text { Type of } \\
\text { OLP } \\
\text { E/NE }\end{array}$} & \multirow[b]{2}{*}{ country } & \multirow{2}{*}{$\begin{array}{l}\text { Genotyping } \\
\text { method }\end{array}$} & \multicolumn{2}{|l|}{ Case } & \multicolumn{2}{|l|}{ control } \\
\hline & & & & & $\begin{array}{l}\text { Number } \\
\text { (male/female) }\end{array}$ & Age & $\begin{array}{l}\text { Number } \\
\text { (male/female) }\end{array}$ & Age \\
\hline Azab NA (15) & 2018 & $4 / 11$ & Egypt & Real time PCR & $15(-/-)$ & $55.1 \pm 8.3$ & $15(-/-)$ & $45 \pm 6.7$ \\
\hline $\begin{array}{l}\text { Al-Mohaya } \\
\text { MA(24) }\end{array}$ & 2016 & - & $\begin{array}{l}\text { Saudi } \\
\text { Arabia }\end{array}$ & ARMS-PCR & $42(16 / 26)$ & $27-72$ & $195(100 / 95)$ & $20-65$ \\
\hline $\begin{array}{ll}\text { Kimkong I } & \text { I } \\
(14) & \end{array}$ & 2012 & $17 / 57$ & Thailand & PCR-SSP & $74(14 / 60)$ & $53.3 \pm 13$ & $268(101 / 167)$ & $29 \pm 9.1$ \\
\hline Bai J (12) & 2008 & $81 / 70$ & China & PCR-SSP & $151(86 / 65)$ & 45 & $143(79 / 64)$ & 45.8 \\
\hline
\end{tabular}

$\mathrm{E}=$ erosive, $\mathrm{NE}=$ non erosive, $\mathrm{ARMS}-\mathrm{PCR}=$ amplification refractory mutation system-polymerase chain reaction, $\mathrm{PCR}$ $\mathrm{SSP}=$ polymerase chain reaction sequence-specific primer

\section{Meta-analysis results}

Allelic model (T vs A)

Four articles reported the frequency of alleles observed in the case and control groups. There were $214 \mathrm{~T}$ alleles in patients with Lichen planus and $408 \mathrm{~T}$ alleles in control group. Heterogeneity between studies was not significant $(\mathrm{Q}$-value $=0.98, \mathrm{df}=3, \mathrm{I} 2=0.00$, $\mathrm{p}$-value $=0.80)$. Based on the results of the meta-analysis using fixed effects model it was observed that the odds of $\mathrm{T}$ vs $\mathrm{A}$ allele were 1.62 times higher than that of the control group. This value was statistically significant $(\mathrm{OR}=1.62 ; 95 \% \mathrm{CI}=1.28-2.04, \mathrm{p}$-value
$<0.001)$. Figure 2 shows the forest diagrams related to the meta-analysis.

Homozygote model (TT vs AA)

Four articles reported the frequency of alleles observed in patients in the control and case groups. Heterogeneity between studies was not significant $(\mathrm{Q}-\mathrm{value}=1.77$, df $=3, \mathrm{I} 2=$ 0.00 , p-value $=0.62$ ). Based on the results of meta-analysis using fixed effects model, it was observed that TT vs AA genotype was 2.67 times higher than control group. This value was statistically significant $(\mathrm{OR}=2.67$; $95 \% \mathrm{CI}=1.6-4.45$; $\mathrm{p}$-value $=<0.001)$. Figure 3 shows the forest diagrams related to the meta-analysis 
Study name

\begin{tabular}{lllllll} 
& \multicolumn{2}{c}{$\begin{array}{c}\text { Odds Lower Upper } \\
\text { ratio }\end{array}$} & limit & limit & Z-Value p-Value \\
Maha Ali M. Al-Mohaya et al(2016) & 1.608 & 0.989 & 2.613 & 1.916 & 0.055 \\
Noha A. Azaba et al(2018) & 1.000 & 0.350 & 2.858 & 0.000 & 1.000 \\
Ingorn Kimkong et al(2012) & 1.760 & 1.192 & 2.600 & 2.841 & 0.004 \\
Jingping Bai et al(2008) & 1.608 & 1.101 & 2.347 & 2.459 & 0.014 \\
& 1.622 & 1.287 & 2.044 & 4.099 & 0.000
\end{tabular}

Odds ratio and $95 \% \mathrm{Cl}$

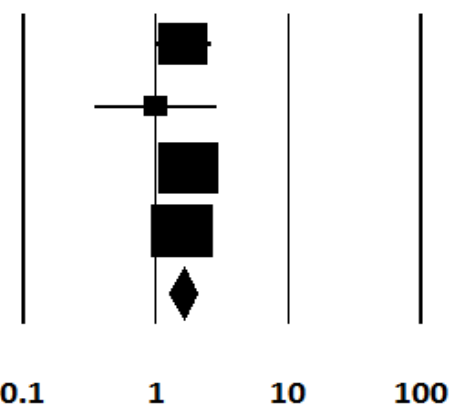

Figure 2: Forest plot of the IFN- $\gamma+874 \mathrm{~A} / \mathrm{T}$ polymorphism and OLP susceptibility in allelic model (T vs A).

$\mathrm{CI}=$ confidence interval, $\mathrm{OR}=$ odds ratio.

\begin{tabular}{|c|c|c|c|c|c|}
\hline \multirow[t]{3}{*}{ Study name } & \multicolumn{5}{|c|}{ Statistics for each study } \\
\hline & \multicolumn{5}{|c|}{ Odds Lower Upper } \\
\hline & ratio & limit & limit & -Value & -Value \\
\hline Maha Ali M. Al-Mohaya et al(2016) & 5.791 & 1.244 & 26.950 & 2.239 & 0.025 \\
\hline Noha A. Azaba et al(2018) & 1.000 & 0.048 & 20.829 & 0.000 & 1.000 \\
\hline Ingorn Kimkong et al(2012) & 2.927 & 1.364 & 6.280 & 2.758 & 0.006 \\
\hline \multirow[t]{2}{*}{ Jingping Bai et al(2008) } & 2.106 & 0.953 & 4.654 & 1.842 & 0.066 \\
\hline & 2.671 & 1.603 & 4.450 & 3.773 & 0.000 \\
\hline
\end{tabular}

0.01

\section{Odds ratio and $95 \% \mathrm{Cl}$}

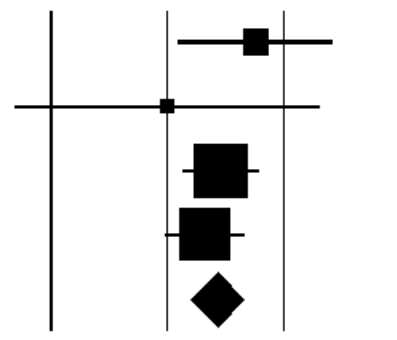

$\begin{array}{llll}0.1 & 1 & 10 & 100\end{array}$

Figure 3: Forest plot of the IFN- $\gamma+874 \mathrm{~A} / \mathrm{T}$ polymorphism and OLP susceptibility in homozygote model (TT vs AA). $\mathrm{CI}=$ confidence interva $\mathrm{OR}=$ odds rati

Heterozygote model (AT vs AA):

Four articles reported the frequency of alleles observed in patients in the control and case groups. Heterogeneity between studies was not significant $(\mathrm{Q}$-value $=4.72$, df $=3, \mathrm{I} 2=$ 36.47 , p-value $=0.19$ ). Based on the results of the meta-analysis using fixed effects model, it was observed that the odds of AT vs AA genotype in Lichen planus patients were 2.67 times higher than the control group. This value was statistically significant $(\mathrm{OR}=1.56$; $95 \% \mathrm{CI}=1.08-2.25, \mathrm{p}$-value $=0.01)$. Figure 4 shows the forest diagrams related to the metaanalysis. 


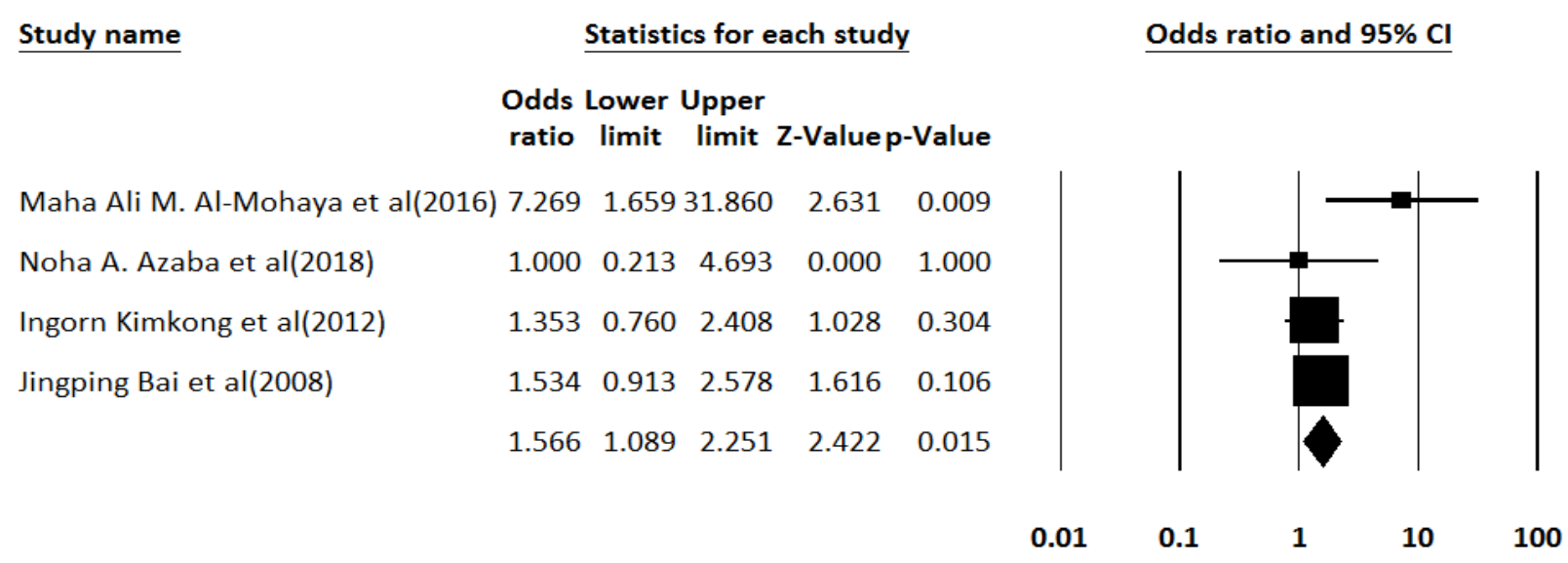

Figure 4: Forest plot of the IFN- $\gamma+874 \mathrm{~A} / \mathrm{T}$ polymorphism and OLP susceptibility in heterozygote model (AT vs $\mathrm{AA}$ ). $\mathrm{CI}=$ confidence interval, $\mathrm{OR}=$ odds ratio.

Recessive model (TT vs AA + AT):

A total of 4 articles were included in the meta-analysis. In patients with Lichen planus, 48 cases had TT genotype and 89 cases in control group. Heterogeneity was not significant between studies (Q-value $=2.65$, $\mathrm{df}=3, \mathrm{I} 2=0.00, \mathrm{p}$-value $=0.44)$. Based on the results of the meta-analysis using fixed effects model, it was observed that the chance of TT vs AA + AT genotype in patients with lichen planus was $1 / 1$ times higher than control group. This value was statistically significant $(\mathrm{OR}=1.73 ; 95 \% \mathrm{CI}=1.13-2.64$, $\mathrm{p}$-value $=0.011)$. Figure 5 shows the forest diagrams related to the meta-analysis.

\section{TT vs $A T+A A$}

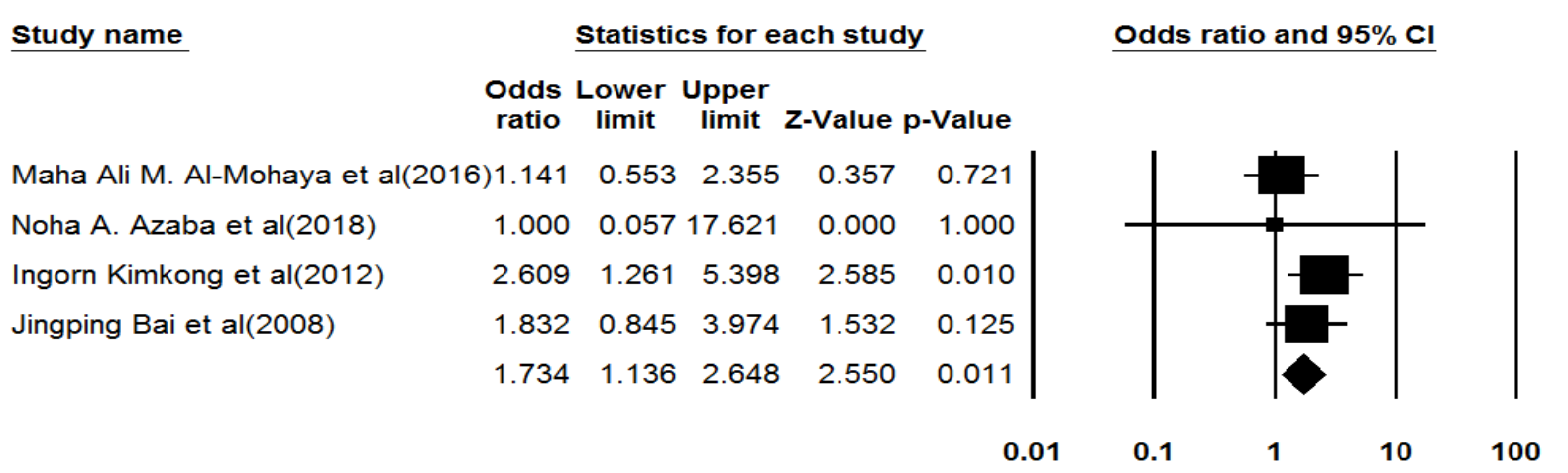

Figure 5: Forest plot of the IFN $-\gamma+874 \mathrm{~A} / \mathrm{T}$ polymorphism and OLP susceptibility in recessive model (TT vs $\mathrm{AA}+\mathrm{AT}) . \mathrm{CI}=$ confidence interval, $\mathrm{OR}=$ odds ratio. 
Dominant model (AT + TT vs AA)

A total of 4 articles were included in the meta-analysis. There were 124 AA genotypes in patients with Lichen planus and 310 in the control group. The amount of heterogeneity between studies was not significant (Q-value $=3.86, \mathrm{df}=3, \mathrm{I} 2=22.33$, $\mathrm{p}$-value $=0.27$ )
Based on the results of meta-analysis using fixed effects model, it was observed that the chances of AT + TT vs AA genotype were 0.57 times higher than that of control group. This value was statistically significant $(\mathrm{OR}=$ $1.75 ; 95 \% \mathrm{CI}=1.28-2.43$, $\mathrm{p}$-value $=0.001$ ). Figure 6 shows the forest diagrams related to the

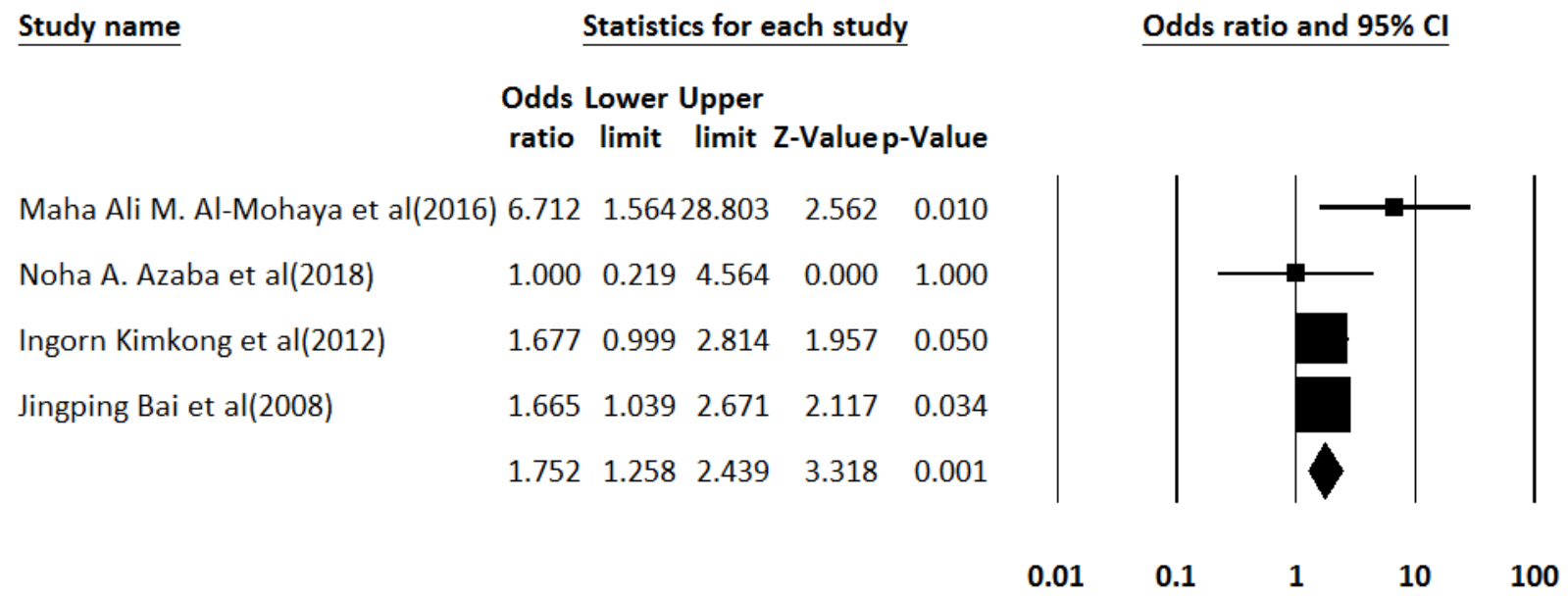

Figure 6: Forest plot of the IFN- $\gamma+874 \mathrm{~A} / \mathrm{T}$ polymorphism and OLP susceptibility in dominant model ( $\mathrm{TT}+\mathrm{AT}$ vs $\mathrm{AA}) . \mathrm{CI}=$ confidence interval, $\mathrm{OR}=$ odds ratio.

\section{Discussion}

Many studies have identified IFN- $\gamma$ as a key role in the pathogenesis of OLP (3-7). Recent studies have also shown links between IFN- $\gamma$ gene polymorphism and OLP (12-14). The purpose of the present study was to identify and systematically analyze all relevant clinical studies to investigate the association of the IFN- $\gamma(+874 \mathrm{~A} / \mathrm{T})$ gene polymorphism and susceptibility to OLP. The present study is the first quantitative evaluation of the association between IFN- $\gamma(+874 \mathrm{~A} / \mathrm{T})$ gene polymorphism and OLP. Three case-control studies and 1 cohort study were selected to evaluate IFN- $\gamma \quad(+874 \quad \mathrm{~A} / \mathrm{T}) \quad$ gene polymorphism in OLP based on inclusion and exclusion criteria. SNP of some genes can alter protein expression, for example there are three possible genotypes for $+874 \mathrm{~T} / \mathrm{A}$ : AA, AT and TT. Each of these genotypes is thought to represent the expression of different levels of IFN- $\gamma(10,11,19-23)$. Following the meta-analysis, there was a positive relationship between IFN $-\gamma(+874$ $\mathrm{A} / \mathrm{T}$ ) gene polymorphism and the risk of OLP. In fact, the $\mathrm{T}$ allele, and the $\mathrm{T}$ allele genotypes (AT and TT genotypes), were more frequently present in OLP than in healthy patients. This finding is similar to the results of studies by Al-Mohaya et al (24), Kimkong et al (14) and 
Bai et al (12). However Azaba et al (15) found no significant association between IFN$\gamma(+874 \mathrm{~A} / \mathrm{T})$ gene polymorphism and the risk of OLP. In a closer look at studies, AlMohaya et al found that IFN- $\gamma(+874$ A/T) gene polymorphism has a significant association with the risk of OLP in the Saudi population (24). The results of the Kimkong et al studies showed that the frequency of the $\mathrm{T}$ allele was significantly higher in Thailand OLP patients than in healthy controls(14). Bai et al also found a higher $\mathrm{T}$ allele frequency in the Chinese population than in the healthy population(12). However, the results of Azab et al studies did not show a significant relationship between IFN- $\gamma(+874 \mathrm{~A} / \mathrm{T})$ gene polymorphism and the risk of OLP disease (15).

This heterogeneity in studies in some comparative models and contradictory conclusions may be attributed to various factors. First, the studies included people from different populations who were conducted in different countries and could be the result of differences in the race of the subjects studied, such as in Saudi Arabia, Thailand, China, and Egypt. Second, it may be the result of different etiologies of OLP. Third, some studies did not use HWE (Hardy - Weinberg equilibrium). Another reason may be related to the low statistical population of some studies.

Similar to this meta-analysis, which shows the association of IFN- $\gamma(+874 \mathrm{~A} / \mathrm{T})$ gene polymorphism and the chance of developing OLP, other studies have shown that this SNP is associated with other diseases as well (2529). Another meta-analysis conducted in 2016 showed a significant relationship between IFN- $\gamma(+874 \mathrm{~A} / \mathrm{T})$ gene polymorphism and the chance of autoimmune diseases(16). These studies demonstrate the importance of this SNP in the development of diseases and the need for further studies to better investigate the role of this SNP. Also in a study reported by et al Marco Carrozzo (13), they identified the first intron of the IFN- $\gamma$ gene promoter as an important risk factor in the development of OLP oral lesions, indicating that other sites of this gene also need to be further investigated.

This meta-analysis may provide further evidence for understanding the pathogenesis and progression of OLP, as well as a pathological basis for physicians to prognosis and better treatment of this disease.

\section{Conflict of interest}

The authors declare that there is no conflict of interest.

\section{References}

1. Tao X, Huang Y, Li R, Qing R, Ma L, Rhodus $\mathrm{NL}$, et al. Assessment of local angiogenesis and vascular endothelial growth factor in the patients with atrophic-erosive and reticular oral lichen planus. Oral Surgery, Oral Medicine, Oral Pathology, Oral Radiology, and Endodontology. 2007;103(5):661-9.

\section{[DOI:10.1016/j.tripleo.2006.05.023]}

2. Liu G-X, Sun J-T, Yang M-X, Qi X-M, Shao $\mathrm{Q}-\mathrm{Q}$, Xie $\mathrm{Q}$, et al. OPN promotes survival of activated $\mathrm{T}$ cells by up-regulating CD44 in patients with oral lichen planus. Clinical Immunology. 2011;138(3):291-8. [DOI:10.1016/j.clim.2010.12.007]

3. Sugerman P, Savage N, Walsh L, Zhao Z, Zhou $X$, Khan A, et al. The pathogenesis of oral lichen planus. Critical Reviews in Oral Biology \& Medicine. 2002;13(4):350-65. [DOI:10.1177/154411130201300405]

4. Zhou ZT, Wei BJ, Shi P. Osteopontin expression in oral lichen planus. Journal of oral 
pathology \& medicine. 2008;37(2):94-8. [DOI:10.1111/j.1600-0714.2007.00599.x]

5. Neurath MF, Finotto S, Glimcher LH. The role of Th1/Th2 polarization in mucosal immunity. Nature medicine. 2002;8(6):567. [DOI:10.1038/nm0602-567]

6. Gray PW, Goeddel DV. Structure of the human immune interferon gene. Nature. 1982;298(5877):859. [DOI:10.1038/298859a0]

7. Schoenborn JR, Wilson CB. Regulation of interferon- $\gamma$ during innate and adaptive immune responses. Advances in immunology. 2007;96:41101. [DOI:10.1016/S0065-2776(07)96002-2]

8. Hamzaoui K, Hamzaoui A, Guemira F, Bessioud M, Hamza MH, Ayed K. Cytokine profile in Behçet's disease patients. Scandinavian journal of rheumatology. 2002;31(4):205-10. [DOI:10.1080/030097402320318387]

9. Danielsson K, Ebrahimi M, Wahlin Y-B, Nylander K, Boldrup L. Increased levels of COX2 in oral lichen planus supports an autoimmune cause of the disease. Journal of the European Academy of Dermatology and Venereology. 2012;26(11):1415-9. [DOI:10.1111/j.1468$\underline{3083.2011 .04306 . x]}$

10. Pravica V, Perrey C, Stevens A, Lee J-H, Hutchinson IV. A single nucleotide polymorphism in the first intron of the human IFN- $\gamma$ gene:: Absolute correlation with a polymorphic CA microsatellite marker of high IFN- $\gamma$ production. Human immunology. 2000;61(9):863-6. [DOI:10.1016/S01988859(00)00167-1]

11. Reichert S, Machulla HK, Klapproth J, Zimmermann U, Reichert Y, Gläser C, et al. Interferon-gamma and interleukin-12 gene polymorphisms and their relation to aggressive and chronic periodontitis and key periodontal pathogens. Journal of periodontology. 2008;79(8):1434-43.

[DOI:10.1902/jop.2008.070637]
12. Bai J, Lin $\mathrm{M}$, Zeng $\mathrm{X}$, Zhang $\mathrm{Y}$, Wang Z, Shen J, et al. Association of polymorphisms in the human IFN- $\gamma$ and IL-4 gene with oral lichen planus: a study in an ethnic Chinese cohort. journal of interferon \& cytokine research. 2008;28(6):351-8. [DOI:10.1089/jir.2007.0056]

13. Carrozzo M, Dametto E, Fasano ME, Arduino $\mathrm{P}$, Broccoletti R, Vezza D, et al. Tumor necrosis factor- $\alpha$ and interferon- $\gamma$ polymorphisms contribute to susceptibility to oral lichen planus. Journal of Investigative Dermatology. 2004;122(1):87-94. [DOI:10.1046/j.0022202X.2003.22108.x]

14. Kimkong I, Nakkuntod J, Sodsai P, Hirankarn $\mathrm{N}$, Kitkumthorn N. Association of interferongamma gene polymorphisms with susceptibility to oral lichen planus in the Thai population. Archives of oral biology. 2012;57(5):491-4. [DOI:10.1016/j.archoralbio.2011.10.009]

15. Azab NA, El Salam LA, Ahmed E, El Sharkawy M, ElSharkawy A, El Asheiry SG. Interferon gamma and interleukin 8 gene polymorphisms in patients with hepatitis $\mathrm{C}$ virus related oral lichen planus. Archives of oral biology. 2018;96:189-94. [DOI:10.1016/j.archoralbio.2018.09.015]

16. Lee $\mathrm{YH}, \mathrm{Bae}$ SC. Association between interferon- $\gamma^{+} 874$ T/A polymorphism and susceptibility to autoimmune diseases: a metaanalysis. Lupus. 2016;25(7):710-8. [DOI:10.1177/0961203315624557]

17. Moher D, Liberati A, Tetzlaff J, Altman DG. PRISMA Group. Preferred reporting items for systematic reviews and meta-analyses: the PRISMA statement. PLoS Med 2009;6:e1000097. [DOI:10.1371/journal.pmed.1000097]

18. Munn Z, Moola S, Lisy K, Riitano D. The Joanna Briggs Institute Reviewers' Manual 2014. The systematic review of prevalence and incidence data. Adelaide, SA: The Joanna Briggs Institute 2014.

19. Camargo MC, Mera R, Correa P, Peek RM, Fontham ET, Goodman KJ, et al. Interleukin- $1 \beta$ 
and interleukin-1 receptor antagonist gene polymorphisms and gastric cancer: a metaanalysis. Cancer Epidemiology and Prevention Biomarkers. 2006;15(9):1674-87.

\section{[DOI:10.1158/1055-9965.EPI-06-0189]}

20. Guo J, Jin M, Zhang M, Chen K. A genetic variant in miR-196a2 increased digestive system cancer risks: a meta-analysis of 15 case-control studies. PloS one. 2012;7(1):e30585. [DOI:10.1371/journal.pone.0030585]

21. Heidari Z, Mahmoudzadeh-Sagheb H, Hashemi M, Ansarimoghaddam S, Moudi B, Sheibak N. Association between IFN- $\gamma$. International journal of dentistry. 2015;2015. [DOI: 10.1155/2015/375359]

22. Ianni M, Bruzzesi G, Pugliese D, Porcellini E, Carbone I, Schiavone A, et al. Variations in inflammatory genes are associated with periodontitis. Immunity \& Ageing. 2013;10(1):39. [DOI:10.1186/1742-4933-10-39]

23. Loo WT, Fan C-b, Bai L-j, Yue Y, Dou Y-d, Wang $\mathrm{M}$, et al., editors. Gene polymorphism and protein of human pro-and anti-inflammatory cytokines in Chinese healthy subjects and chronic periodontitis patients. Journal of translational medicine; 2012: BioMed Central. [DOI:10.1186/1479-5876-10-S1-S8]

24. Al-Mohaya MAM, Al-Otaibi L, Al-Harthi F, Al Bakr E, Arfin M, Al-Asmari A. Association of genetic polymorphisms in interferon- $\gamma$, interleukin- 6 and transforming growth factor- $\beta 1$ gene with oral lichen planus susceptibility. BMC oral health. 2016;16(1):76. [DOI:10.1186/s12903016-0277-x]
25. De Albuquerque A, Rocha L, de Morais Batista A, Teixeira A, Dos Santos D, Nogueira N. Association of polymorphism+ $874 \mathrm{~A} / \mathrm{T}$ of interferon- $\gamma$ and susceptibility to the development of tuberculosis: meta-analysis. European Journal of Clinical Microbiology \& Infectious Diseases. 2012;31(11):2887-95. [DOI:10.1007/s10096-0121660-4]

26. Holla LI, Hrdlickova B, Linhartova P, Fassmann A. Interferon- $\gamma+874 \mathrm{~A} / \mathrm{T}$ polymorphism in relation to generalized chronic periodontitis and the presence of periodontopathic bacteria. archives of oral biology. 2011;56(2):153-8. [DOI:10.1016/j.archoralbio.2010.09.005]

27. Liu N, Song Y, Shi W. IFN- $\gamma+874$ T/A polymorphisms contributes to cervical cancer susceptibility: a meta-analysis. International journal of clinical and experimental medicine. 2015;8(3):4008.

28. Silva G, Naveca F, Ramasawmy R, Boechat A. Association between the IFNG+ 874A/T gene polymorphism and leprosy resistance: a metaanalysis. Cytokine. 2014;65(2):130-3. [DOI:10.1016/j.cyto.2013.12.002]

29. Sun Y, Lu Y, Pen Q, Li T, Xie L, Deng Y, et al. Interferon gamma+ $874 \mathrm{~T} / \mathrm{A}$ polymorphism increases the risk of cervical cancer: evidence from a meta-analysis. Tumor Biology. 2015;36(6):4555-64. [DOI:10.1007/s13277-0153100-4]

\section{How to cite:}

Motahari P, Pournaghi Azar F, Rasouly P: Association of Interferon-gamma Gene Polymorphism (+874 A/T) and Oral Lichen planus susceptibility: Systematic Review and Meta-Analysis. Jorjani Biomedicine Journal. 2019; 7(3): 45-55. 